\title{
A RELAÇ̃̃O ENTRE ESTUDANTES E POBREZA NA CAIXA DO ESTUDANTE POBRE EDELWEISS BARCELLOS DA UNIVERSIDADE DE MINAS GERAIS (1932-1935)
}

Alice da Conceição Christófaro* Laerthe de Morais Abreu Junior**

RESUMO: Este artigo tem por objetivo analisar o discurso sobre a pobreza dos estudantes dos cursos superiores da Universidade de Minas Gerais que solicitaram auxílio da Caixa do Estudante Pobre Edelweiss Barcellos (CEPEB) no recorte de 1932 a 1935, destacando as relações de poder e a produção de enunciados que buscavam o convencimento dos sujeitos envolvidos no aval dos pedidos e os jogos e efeitos de verdade para conquistar essa ajuda. A escolha para a análise desse tema está relacionada com a perspectiva foucaultiana sobre o discurso e a produção dos efeitos de verdade. Os enunciados que compõem esses documentos da CEPEB apontaram para a existência de uma formação discursiva sobre a pobreza dos estudantes, que vai além das carências materiais. Eram estabelecidas relações entre esses estudantes e a sociedade em geral, em que aconteciam manifestações de amizade, dependência e auxílio.

Palavras-chave: Universidade de Minas Gerais; Pobreza; Assistência.

\footnotetext{
* Doutoranda em Educação pela Faculdade de Educação (FaE) da Universidade Federal de Minas Gerais (UFMG). E-mail: alicechristofaro@hotmail.com

* * Doutor em Educação pela Universidade Metodista de Piracicaba (UNIMEP); Professor Adjunto da Universidade Federal de São João del Rei. E-mail: laerthejr@yahoo.com.br
} 


\section{THE RELATIONSHIP BETWEEN STUDENTS AND POVERTY AT THE} EDELWEISS BARCELLOS STUDENT AIDING FUND AT UNIVERSITY OF MINAS GERAIS (1932-1935) ABSTRACT: This article aims to analyze the discourse on poverty among students of higher education courses at the University of Minas Gerais who requested aid from the Caixa do Estudante Pobre Edelweiss Barcellos (CEPEB) in the period from 1932 to 1935. It highlights the power relations, the production of utterances that sought to convince those involved in the approval of applications, and the truth effects used to help achieve this. The choice for analysis of this issue relates to the Foucauldian perspective on discourse production and truth effects. The statements that form the corpus of CEPEB documents pointed out the existence of a discursive formation regarding the poverty of students, which goes beyond material deprivation. Relations were established between such students and society and these featured expressions of friendship, dependency and assistance.

Keywords: Universidade de Minas Gerais; Poverty; Assistance.

\section{Introdução}

No campo da historiografia da educação brasileira das décadas iniciais do século $\mathrm{XX}$, há dois temas de pesquisa poucos explorados. $\mathrm{O}$ primeiro diz respeito à presença de estudantes nos cursos superiores: suas histórias de vida escolar até seu ingresso e suas trajetórias durante o curso e depois da formação. O segundo tema, diretamente envolvido com o primeiro, volta-se para a situação socioeconômica dos estudantes - além de aspectos culturais e psicológicos também - numa época em que as dificuldades de acesso ao ensino superior eram muito grandes. Assim, torna-se fundamental pesquisar a relação entre pobreza e ensino superior. Com isso, faz-se necessário, além de compreender os percursos e trajetórias dos estudantes, observar os discursos sobre a pobreza, buscando os "diferentes discursos que compõem o campo dessa produção de enunciados sobre a pobreza, construindo o seu lugar, seus traços, seus significados e seus sentidos, seu espaço político e moral" (LIMA, 2005, p.58).

Este artigo tem por objetivo analisar o discurso sobre a pobreza dos estudantes dos cursos superiores da Universidade de Minas Gerais que solicitaram auxílio à Caixa do Estudante Pobre Edelweiss Barcellos (CEPEB), destacando as relações de poder e a produção de enunciados que buscavam o convencimento dos sujeitos envolvidos no aval dos pedidos e os jogos e efeitos de verdade para conquistar essa ajuda. A CEPEB 
foi uma associação criada pelo governo mineiro para auxiliar os autodeclarados estudantes pobres de Belo Horizonte no pagamento de matrículas, mensalidades, taxas, compra de livros e despesas indiretas (vestuário, tratamento de saúde e moradia) no início da década de 1930. Há vasta documentação disponível nos arquivos da atual UFMG relativa aos anos de 1932 a 1935. Dessa documentação, foram selecionados para este trabalho os questionários de pedidos de alunos e os livros com registros das sindicâncias realizadas, bem como a troca de correspondência relativa aos pedidos.

A Universidade de Minas Gerais (UMG) foi formalmente criada em 1927 pela Lei 956, de 07 de setembro, aglutinando as faculdades que já funcionavam em Minas Gerais: a Faculdade Livre de Direito, a Faculdade de Medicina, a Escola de Odontologia e Farmácia e a Faculdade de Engenharia, todas criadas na passagem do século XIX para o século XX. Apesar da constituição da UMG, tais faculdades continuaram a funcionar em prédios separados e distantes fisicamente, até que, a partir da década de 1930, começaram as iniciativas para a criação de uma cidade universitária. ${ }^{1}$

\section{A assistência na UMG e a CEPEB}

De acordo com as considerações de Foucault (2009), para apreender a formação de um objeto do discurso (no caso, a condição de pobreza dos estudantes que recorriam à CEPEB), é necessário, inicialmente, que se demarquem as superfícies de emergência das primeiras noções sobre o objeto, determinando seus espaços e sujeitos de circulação e analisando as diferenças individuais de acordo com as características de racionalização do contexto. Além disso, é preciso que se delimitem suas instâncias de circulação e colocação, para que, em seguida, sejam observadas suas grades de especificação ou sistemas de classificação, oposição, demarcação e associação.

Assim, quando se propõe compreender os discursos sobre a pobreza presentes nos documentos da CEPEB, é necessário identificar a superfície da emergência desses discursos: que documentos selecionar? Cartas? Questionários? E ainda: quem os fez circular e de que forma? Qual o contexto em que estavam inseridos? Assim, uma série de cruza- 
mentos se faz nessas superfícies de produção de discursos em que se deve atentar também para os efeitos de verdade que atravessam esses discursos (tanto dos pedidos quanto das sindicâncias), já que está em jogo aqui a permanência de estudantes autodeclarados pobres num espaço social que não lhes é fácil percorrer.

As primeiras iniciativas de auxílio a estudantes pobres nos cursos superiores mineiros foram encontradas na década de 1910, apesar de haver registros de cessão de bolsas de estudos a alunos da Escola de Minas de Ouro Preto em 1853. Essas bolsas não eram destinadas àqueles estudantes sem condições de manutenção dos cursos, mas sim a atraí-los para tal escola recém-criada, visto que a quantidade de estudantes nesse curso era pequena.

Em 1912, as Fundações Affonso Penna e Barão do Rio Branco iniciaram suas atividades na Faculdade Livre de Direito. Elas passaram a realizar atividades que envolviam estudantes, professores e cidadãos da sociedade, voltadas à assistência, publicação de revistas e premiação dos alunos que mais se destacassem. Entretanto, não se pode excluir a possibilidade da existência de outras associações, grêmios ou espaços de sociabilidade entre os estudantes, anteriores a esse período.

A partir de 1915, já havia iniciativas de organização entre os estudantes de todos os cursos superiores da capital mineira, constantes nos registros do planejamento de criação da Confederação dos Estudantes de Minas Gerais. Entretanto, somente com a fundação da UMG, as associações estudantis se organizaram em torno da Associação Universitária Mineira (AUM), cujo estatuto de funcionamento foi elaborado somente em 1931. Uma de suas finalidades, dentre outras, seria "integrar a obra de educação universitária, aperfeiçoando-a do ponto de vista moral, intelectual e physico" (ESTATUTO DA AUM, 1931). Foram formadas várias comissões, dentre elas a Comissão de Assistência, que se responsabilizava por auxiliar sigilosamente os estudantes que não tivessem condições de manter seus estudos.

Entretanto, com as mudanças político-administrativas ocorridas na UMG em 1930, a partir da renúncia do Reitor Francisco Mendes Pimentel e a consequente intervenção do Governo do Estado, além das alterações previstas pelo Estatuto das Universidades Brasileiras de 1931, a AUM teve suas ações enfraquecidas, surgindo, nesse contexto, a Caixa do Estudante Pobre Edelweiss Barcellos (CEPEB). A CEPEB funcionou presidi- 
da pela terceira Rainha dos Estudantes, Daisy Prates, porém seu nome homenageia sua criadora, a segunda Rainha dos Estudantes, Edelweiss Barcellos. ${ }^{2}$

\section{0 plano da pesquisa}

Para esta pesquisa, dentre os 110 questionários existentes nos documentos da CEPEB, foram selecionados 54 pedidos de auxílio, de acordo com o seguinte critério: deveriam ser questionários de estudantes que solicitavam matrícula ou pagamento de mensalidades para algum curso da UMG, considerando que o estudante que solicitava acesso ou matrícula, pelas normas da legislação de ensino da época, já teria frequentado algum curso ou alguma aula preparatória e, dessa forma, tivera contato com o discurso sobre a pobreza que circulava no meio acadêmico.

Do total de questionários analisados, 35 questionários (64\%) apresentam a carta justificativa e 19 (35\%) questionários não a apresentam. Algumas cartas justificativas são extensas, ocupando quase toda a folha e fornecendo muitos detalhes sobre a situação dos estudantes. A média de idade dos estudantes era de 26 anos.

Dos 54 estudantes que recorreram ao auxílio, 19 (35\%) deles trabalhavam, sendo que, destes, quatro trabalhavam em jornais para se sustentarem nos estudos. Os outros empregos ocupados pelos demais estudantes requerentes eram: auxiliar de escritório, servente e militar da Força Pública Mineira, professor, oficial do Arquivo Público Mineiro, fiel (sic) tesoureiro da Secretaria do Interior, guarda de abrigo de menores, escrevente da Loteria Mineira, interno do Instituto Raul Soares e laboratorista do Instituto Biotherápico.

Quase metade dos estudantes que requereram o auxílio da CEPEB para o ensino superior tinha algum tipo de empréstimo: há 25 questionários $(46 \%)$ que faziam essa referência, o que indica que, provavelmente, quem recorria à CEPEB já teria recorrido a outro meio para conseguir contornar suas dificuldades.

Quanto à condição familiar, três estudantes $(5,5 \%)$ já tinham o pai e a mãe falecidos, sete estudantes (13\%) tinham apenas o pai falecido e quatro estudantes $(7 \%)$ tinham apenas a mãe falecida. Assim, a maioria dos estudantes $(93 \%)$ teria algum genitor responsável vivo. 
A média de filhos em cada família era de cinco, sendo que a média de filhos estudando era de quatro. Apenas oito estudantes (15\%) não declararam o emprego que pais ou tutores ocupavam. As profissões que os pais ocupavam eram: administrador de matadouro, comércio, condutor postal, dirigente de lar de menores, escrivão do crime, exportador de aves, farmacêutico, fazendeiro, funcionário público, inspetor de alunos, lavrador, mascateador, operário e tabelião de termo judiciário. Três estudantes indicaram que seus pais estavam desempregados.

Oito alunos (15\%) solicitaram auxílio para os cursos de Agronomia e Medicina Veterinária, 15 alunos (28\%), para o curso de Direito, três alunos (5\%) para o curso de Engenharia, seis alunos (11\%) para os cursos de Odontologia e Farmácia e 21 alunos (39\%) para o curso de Medicina. Como se pode notar, os cursos de Direito e Medicina eram os mais procurados para auxílio por parte dos estudantes autodeclarados pobres na UMG, ou seja, 67\% dos questionários analisados correspondiam a estudantes desses dois cursos. Esse fato pode estar relacionado com o maior número de alunos inscritos nesses cursos, o que, proporcionalmente, aumentava o número de alunos que necessitavam de ajuda para prosseguir nos estudos.

Ao analisar quantos pedidos foram atendidos pela CEPEB, Portes (2005) apontou que 94 dos 281 estudantes tiveram suas solicitações aceitas, afirmando ainda que a CEPEB "priorizava sobremaneira os estudantes de Medicina (38,3\%), os de Direito (32\%) e os de Odontologia e Farmácia (14,9\%)" (PORTES, 2005, p.120).

Pelos questionários analisados, percebe-se o aumento do movimento da CEPEB a partir de 1932, pois, naquele ano, seis estudantes (11\% do total analisado) preencheram o questionário solicitando auxílio e, no ano de 1934, foram registrados 31 questionários de estudantes dos cursos superiores (57\%). Em 1935, a demanda caiu para 11 estudantes (20\%), e não há questionários no ano de 1936 e nos anos seguintes. Parece que, em virtude das mudanças administrativas e didáticas pelas quais a UMG passou a partir de 1931 e ainda pelos reflexos da Revolução de 1930, os estudantes passaram a ter maiores dificuldades para o pagamento das taxas, por isso aumentou a procura de auxílio da CEPEB. A partir de 1936, passaram a acontecer movimentações para a criação da Fundação Mendes Pimentel, que assumiu as ações de assistência e cuja atividade se estende até nossos dias. 


\section{Os questionários da CEPEB e a produção de efeitos de verdade}

Os questionários de pedido de auxílio à CEPEB são documentos com três folhas em formulário com cabeçalho preenchido "Caixa do Estudante pobre (sic) Edelweiss Barcellos - Belo Horizonte - Minas Gerais Pedido de Auxílio". Tais questionários provavelmente eram impressos e distribuídos, pela CEPEB ou por outros órgãos vinculados à UMG, aos estudantes que recorriam a seu auxílio.

Na primeira folha do questionário, há os campos para preenchimento da identificação do estudante, tais como nome, idade, local de nascimento e endereço do estudante, tanto no interior (no caso de estudantes vindos de outras cidades), quanto na capital mineira. Há um campo destinado ao preenchimento resumido do pedido com a pergunta: "Que deseja?”. Ainda nessa página, há espaços para que o estudante requerente fornecesse informações sobre sua trajetória escolar, ocupação, emprego, empréstimos e se já recebia algum tipo de auxílio.

$\mathrm{Na}$ segunda página, há campos específicos para informações sobre a previsão de despesas para o ano corrente - cama, mesa, vestimenta, livros e objetos de uso escolar, condução, extraordinários, pagamento de matrícula e extras de ordem escolar. Em seguida, vinha a seguinte pergunta: "Por que sua família, parentes ou amigos não o auxiliam no seu curso? Declare o motivo".

Ao fim dessa folha e no início da seguinte, há campos para o estudante descrever sua família: número de pessoas, renda familiar, profissão do pai ou tutor, quantas pessoas são dependentes dele e quantos filhos se encontram estudando e colocados (sic).

Em seguida, nessa última folha, há espaço para o estudante colocar os nomes das pessoas para referências à consulta sobre sua condição. O questionário traz o seguinte enunciado para esse campo: "Declaro que todas as respostas acima são verdadeiras. Apresento como conhecedoras da minha situação financeira três pessoas idôneas". Tal observação mostra que o estudante deveria responder ao questionário com sinceridade e que as pessoas que ele indicasse deveriam atestar a veracidade das informações que ele prestava.

Logo adiante, aparece a seguinte "observação" da CEPEB: 
OBSERVAÇÃO: Lembre-se de que a Caixa do Estudante Pobre 'Edelweiss Barcellos' não é uma instituição de caridade. Seus recursos provêm em grande parte da contribuição de cada um dos seus colegas. Você deve ser suficientemente orgulhoso e altivo para não solicitar um favor sem o firme propósito de devolvê-lo no futuro, de modo que outros igualmente honestos, mas transitoriamente faltosos de recursos, possam beneficiar-se das mesmas facilidades que agora lhe são proporcionadas.

Não se melindre com as exigências deste questionário. Ele servirá como prova da sua situação atual, bem como para o confronto com outros similares, quando o número de solicitações fôr superior ao das possibilidades da Caixa. Êle será mantido confidencialmente e debaixo de um sigilo absoluto, sob pena de trair aos fins a que se propõe a Caixa do Estudante Pobre 'Edelweiss Barcellos'.

Antes de nos enviar este questionário, você deve ler os estatutos da Caixa. (QUESTIONÁRIO da Caixa do Estudante Pobre Edelweiss Barcellos, folha para solicitação de auxílio, 1932)

Pelo que se pode notar, o texto propõe um desafio: que o estudante passe a participar, como num jogo, entre dizer a verdade e ser beneficiado ou arriscar-se a ser moral e depreciativamente julgado. Há regras explícitas nesse jogo, como a devolução do empréstimo e o sigilo dos dados. A verdade é condição essencial para o alcance do benefício e por isso deve ser exposta pelo estudante ao preencher o questionário na parte em que revela a sua condição. Essa verdade não é um objeto de vergonha ou de melindre; pelo contrário, é a exigência moral, pois as informações serão analisadas e comparadas às verdades ditas pelos demais estudantes que recorreram ao auxílio mediante um conjunto de procedimentos da diretoria da Caixa.

Ao se declararem pobres, os estudantes produziam, em seus questionários, verdades pelas quais eles buscavam comprovar sua condição de pobreza. No entanto, essa exigência era uma forma de confissão que tinha o sentido de uma sujeição dos estudantes, que precisavam se conformar às regras de declaração e de compromisso num jogo de sentidos sobre a pobreza. Candiotto, ao analisar a questão da confissão de acordo com os estudos de Michel Foucault, apontou que:

A confissão configura o ato verbal pelo qual o indivíduo, mediante reconhecimento sobre o que é ou fez, ata-se à sua verdade na relação de dependência a outrem, modificando assim a relação que tem consigo. Vale ressaltar que o reconhecimento da identidade do sujeito a partir da enunciação de sua verdade constitui efeito de relações de poder, da obediência a outrem, tratando-se de 
um processo em que a subjetivação é constituída de modo assujeitado. A produção de verdade prescinde da relação consigo, sendo dependente de tecnologias imanentes a mecanismos do saber-poder (CANDIOTTO, 2010, p.72) (Grifos do autor).

Pelo que se pode perceber, os discursos sobre a pobreza dos estudantes que recorriam à CEPEB eram produzidos dentro de uma ordem. Essa ordem envolve processos de separação e exclusão, criando o que Foucault (2010) chamou de "condições de funcionamento dos discursos", e que tinham o sentido de

[...] impor aos indivíduos que os pronunciam um certo número de regras e assim não permitir que todo mundo tenha acesso a eles. Rarefação, desta vez, dos sujeitos que falam; ninguém entrará na ordem do discurso se não satisfizer certas exigências ou se não for, de início, qualificado para fazê-lo. Mais precisamente: nem todas as regiões do discurso são igualmente abertas e penetráveis; algumas são altamente proibidas (diferenciadas e diferenciantes), enquanto outras aparecem quase abertas a todos os ventos e postas, sem restrição prévia, à disposição de cada sujeito que fala (FOUCAULT, 2010, p.36$37)$.

Quando são analisados os discursos sobre a situação de pobreza dos estudantes da CEPEB, percebe-se que o que se fala não pode ser dissociado de quem fala. $\mathrm{O}$ estudante fala sobre sua pobreza, sua situação. As pessoas ditas idôneas indicadas nas sindicâncias falam como conhecedoras daquela situação de carência. Todos se manifestam como se a pobreza fosse uma verdade palpável que faz parte de uma realidade inescapável: um país carente, em que a presença corriqueira da falta de dinheiro, de condições de moradia adequada, de saúde e de tantas outras carências decorrentes engendra compromissos de natureza diversa para seu enfrentamento. Com isso, pode-se considerar que o funcionamento das sindicâncias da CEPEB era como um ritual, pois

[...] o ritual define a qualificação que devem possuir os indivíduos que falam (e que, no jogo de um diálogo, da interrogação, da recitação, devem ocupar determinada posição e formular determinados tipos de enunciados); define os gestos, os comportamentos, as circunstâncias, e todo o conjunto de signos que devem acompanhar o discurso; fixa, enfim, sua eficácia suposta ou imposta sobre aqueles aos quais se dirigem os limites de seu valor de coerção (FOUCAULT, 2010, p.38-39). 
A comissão de sindicância da CEPEB, assim como a diretoria e a presidente Daisy Prates, os estudantes e as pessoas ditas idôneas consultadas nas sindicâncias eram indivíduos que, ao serem convidados a se pronunciar, passavam a ocupar um lugar privilegiado de articulação dos enunciados na produção discursiva sobre a pobreza: carente de recursos, condições precárias, necessitado, esforçado, faltosas condições, amontoado de dificuldades, vicissitudes, ordenado miserável, irrisória quantia, pobres verdadeiramente pobres.

As partes dos questionários que trouxeram maior quantidade de enunciados sobre a pobreza dos estudantes foram as cartas justificativas e as respostas à pergunta "Por que sua família, parentes ou amigos não o auxiliam durante o seu curso? Declare o motivo?". Pelo que se pode perceber, nessas duas partes, o estudante declarava, de forma mais solta e aberta, a sua condição.

Nota-se que essa produção não está presa a um sentido único, mas que se encontra uma dispersão dos enunciados, uma vez que a singularidade de cada texto discorre sobre uma característica da pobreza. Com isso, é possível afirmar que analisar quantitativamente esses enunciados não é relevante, pois não há como mostrar o aspecto dominante do sentido da pobreza.

É importante destacar que não se pode tomar somente esses enunciados como indicativos da formação do discurso sobre a pobreza dos estudantes que frequentaram a UMG na década de 1930 e recorreram à CEPEB. É preciso que sejam analisadas suas falas em sua complexidade de detalhes, buscando os mínimos indícios que apontem para o sentido dessa pobreza que esses estudantes compreendiam e viviam. Para Abreu Júnior, "é preciso penetrar nas brechas, tomar partido da existência das falhas para chegar ao ponto mínimo do detalhe" (ABREU JÚNIOR, 2005, p.149).

Ao longo dos questionários, é possível notar que os estudantes se referiam a dois elementos que se relacionavam de forma contínua e inseparável: sua condição como estudante e sua condição no meio familiar. Essas duas posições do estudante que fala, que está na ordem de seu discurso, fornecem os elementos necessários para que se possa compreender qual o sentido da pobreza que os próprios estudantes escolheram para convencer os avaliadores do questionário.

A seguir, reproduzimos o questionário integral do estudante José Custódio de Assis Martins, com 21 anos, que pediu auxílio para pagamen- 
to da matrícula no $1^{\circ}$ ano do curso de Engenharia Civil, da Escola de Engenharia, a partir da $2^{\mathrm{a}}$ prestação, no ano de $1933 .^{3}$

\section{FIGURA 1 - Página 1 do questionário de pedido de auxílio à CEPEB do estudante José Custódio de Assis Martins, 1933}

CAIXA DO ESTUDANTE POBRE "EDELWEISS BARCELLOS:

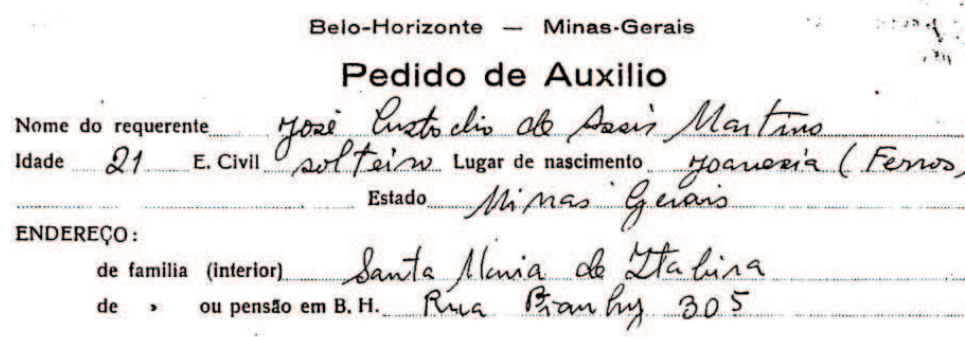

Que desejar Custlio de mishs matricula no $1:$ an o do enrso de Engenhainir civinl a partir da. $2 \leqslant$ prestac: io $^{2}$

Com relação ao requerente:

$3_{3}$ Si o requerente for casado, éxponha cläramente sụă situaçáo com referencia aos filhos e ocupaça extra. domestica da esposa Qual o colegio que cursou antes de entrar para a irademia? Gimasio Lial America
no de Ita fina

Quais as suas ocupaçōes durante a vida colegial? Enxpregado mum sal añ. de bilhar e depois leciomei particuicanmente Ocupa atualmente algum emprego? ...Now

Onde? Desde quando?

Qual o cargo ? Vencimentos mensaes

Recebe alguma mezada de pais ou parentes? $N$.

Contralu algum emprestimo para custear estudos? him

Com quem? Francis co Samuel da Coste Lage 
FIGURA 2 - Página 2 do questionário de pedido de auxílio à CEPEB do estudante José Custódio de Assis Martins, 1933

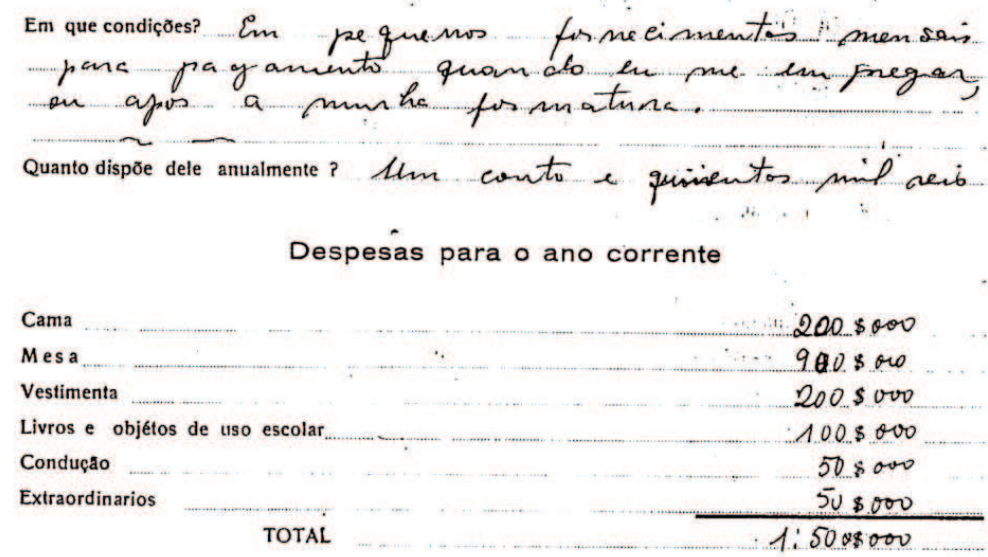

\footnotetext{
Pagamento de matricula (completa) Extras de ordem escolar 25.000

Total das despesas dé manutençầo pessôal e de curso $4.95 \$ 000$ Porque sua familia, parentes ou amigos năo o áuxiliam durante o seu curso ? Declare o motivo $p_{02}$ falta de reensos peenmiarios.

Com relação á familia:

Nome dos pais Fansto Manturs da losta (Faleciab) Maria Felizanck de Ssis Ocupação do pai (ou tutor) ... Naw ten ho tutor por ser maior Qual a sua renda anual? (Inclua salario, juros, dividendos) Nen huma Quantos filhos tem ?. Seis Quantos dependem diretamente dele? Qnatwo Idem com relação a outras pessôas ?
} 
FIGURA 3 - Página 3 do questionário de pedido de auxílio à CEPEB do estudante José Custódio de Assis Martins, 1933

Quantos filḥos recebem educaçẫo? Lloin

na. escol.

no colegio Uh

na acadernia thm

Qual aproximadamente a receita anual da sua familia? Dois Contes de ren's. Quantos irmãos se acham colocados? 29ois

Discrimine a situação geral de cada um Uma easada e outra esta.

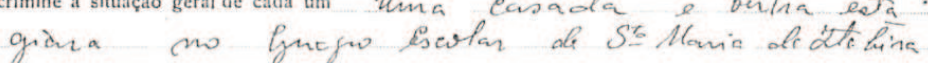

Não tem ofertas, ou promessas de auxilio ? Now

Declaro, que todas as respostas acima são verdadeiras Apresento como conhecedoras da minha situaçâo financeira, tres pessôas idoneas.

Nome Qty da Coston iforge

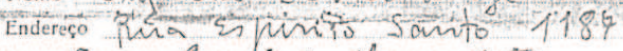

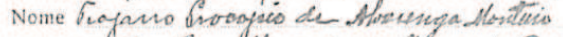

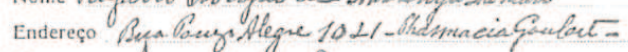

Nome Agenor Grevia

Endereço Sfo Marbi de trabia

OBSERVACุÃO - Lembre-se que a Caixa do Estudante Pobre "Edelweiss Barcellos", nẫo é uma instituiçẫo de caridade. Seus recursos provém em grande parfe da contributiçũo de cada um dos seus colegas. Você deve ser suficienteniente orgulhoso e altivo para não solicitar um favor sem o firme proposito de devolve-lo de futuro, de modo que outros igualmente honestos, mas iransitoriamente faltos de recursos, possam beneficiar-se das mesmas facilidades que agora the sĩo proporcionadas.

Não se melindre com as exigencias deste questionario. Ėle servirí como prova da sua situação atual, bem como para o confronto com outros similares, quando o numero de solicitaçōes fôr superior ao das possibilidades da Caixa. Ele será mantido confidencialmente e debaixo de um sigilo absoluto, sob pena de trair nos fins a que se propõe a Caixa do Estudante Pobre "Edelweiss Barcelios".

Antes de nos enviar este questionario, você deve lêr os estatutos da Caixa.

Belo-Horizonte, 22 de abil de 1933

(Assinado) Mosi luatochio de Deari Martins. 
FIGURA 4 - Página 4 (Justificativa) do questionário de pedido de auxílio à CEPEB do estudante José Custódio de Assis Martins, 1933

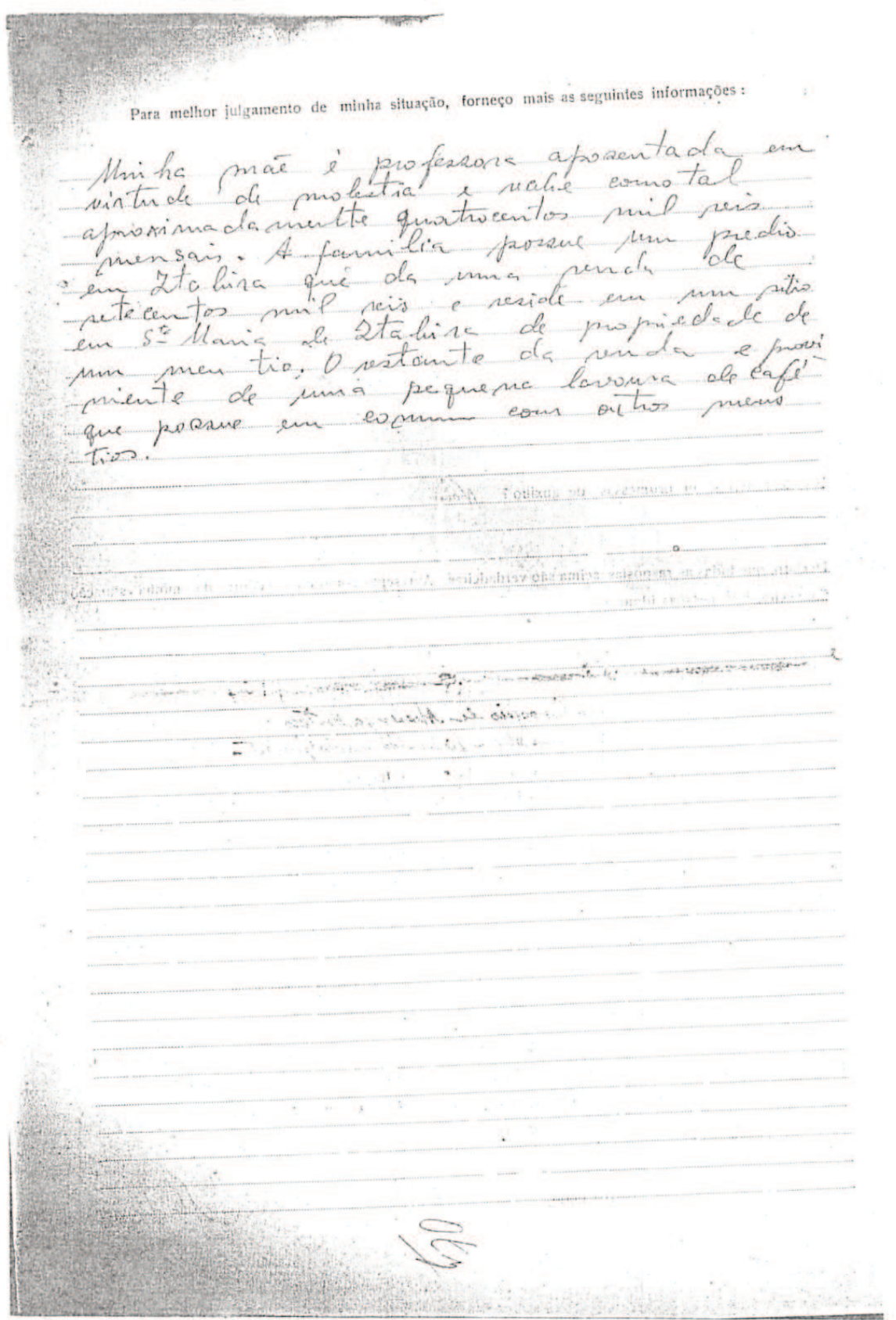




\section{Os enunciados dos estudantes}

Os estudantes, ao relatarem sua condição de pobreza e necessidade do auxílio da CEPEB, produzem situações não só de carências materiais, mas também de necessidade de trabalho, que seria uma possibilidade para a manutenção dos estudos.

Assim, ao se referir às suas despesas como estudante, Edson Parreira, de 17 anos, que recorreu à CEPEB para matrícula no $1^{\circ}$ Ano da Escola de Odontologia e Farmácia, descreveu a situação na qual se encontrava:

Estudei sempre até hoje em estabelecimentos onde as matrículas eram mais módicas porque já tenho dificuldades financeiras desde o $3^{\circ}$ anno do curso primário. Terminando agora o curso gymnasial augmentaram consideravelmente as minhas despezas porque o curso superior é muito mais caro. Pelas razoes acima parece-me que não poderei concluir o curso sem um auxílio qualquer ou da "Caixa do Estudante Pobre" ou de um particular.

Quando abordavam a condição em que se encontravam como alunos, alguns dos estudantes que preencheram os questionários mostraram uma realidade em que a carência material estava sempre muito presente, não só nas despesas diretas com sua escolarização - livros, cadernos, materiais e taxas - como também nas indiretas - transporte e moradia. Os relatos, encontrados em meio aos demais enunciados, são indícios daquilo que se constituía materialmente como pobreza.

João Batista de Castro Costa, aluno do curso de Odontologia, narrou sua situação de moradia da seguinte forma: "quanto às dispesas de cama, mesa não gasto nada pois vou residir em casa de um amigo, que muito conhece a minha situação e de meus pais tudo por isso convidouse a residir com ele" (sic). Em um outro questionário, o aluno daquele mesmo curso, Raphael Walentino, ao solicitar auxílio para o pagamento das taxas para os exames finais, relata que "também encontro sérias dificuldades em adquirir livros e outras cousas escolares. E os principaes livros que possuo foram comprados um a um, isto é, um em cada pagamento, e, ainda hoje, faltam alguns".

As dívidas eram uma constante na vida dos estudantes, ora por precisarem saldar empréstimos anteriores, ora por necessidades do momento, tais como: doenças, viagens, gastos familiares e até mesmo com 
a AUM. Foram encontradas, nos questionários, referências a empréstimos já realizados pela AUM e pela CEPEB aos estudantes, além de empréstimos de terceiros: conhecidos, parentes e pessoas de posição social elevada na época.

A promessa de devolução, conforme as regras da Caixa, aparece claramente em diversos questionários, talvez como condição da concessão do auxílio:

A Caixa dos Estudantes Pobres não esperará muito, pois não deixarei de, em todos pagamentos que receber, dar uma pequena importância por conta. Importuno-os apenas porque acho doloroso perder os exames depois de ter luctado com um amontoado de dificuldades e de estar convenientemente preparado. Esperando ser merecedor da attenção dos dirigentes da benéfica 'Caixa do Estudante Pobre' apresento-lhes desde já o meu melhor e mais sincero agradecimento (QUESTIONÁRIO do aluno de Medicina Veterinária Raphael Valentino, 23 fev. 1934).

Os relatos, nas justificativas e nas cartas de pedido de auxílio endereçadas à CEPEB, especialmente a Daisy Prates, a rainha dos estudantes, sobre as histórias de vida desses solicitantes, apontam para trajetórias em que, corriqueiramente, são relatadas dificuldades e escassez de recursos materiais, luta por trabalho e o estudo como tábua de salvação de uma vida cheia de sacrifícios. O aluno do curso de Medicina Veterinária e Agronomia, Abelardo de Andrade Barroso, deixa transparecer esse discurso na justificativa em seu questionário:

O princípio de minha vida foi muito trabalhoso devido à minha ingrata profissão de photografo, que no interior pouco rende ou quase nada. Taes foram minhas decepções que ultimamente deliberei-se procurar no campo dos estudos o meio mais fácil para combater as vivissitudes (sic) que se nos apareceu, as sircunstancias (sic) várias que apareceram a todo instante na vida daquelle que se acha em condições precárias como eu. (QUESTIONÁRIO do aluno de Medicina Veterinária e Agronomia Abelardo de Andrade Barroso, 14 de maio 1935)

Antônio Macário dos Santos, aluno da Faculdade de Agronomia e Medicina Veterinária, em 1933, narrou as dificuldades que teve para prosseguir com o curso, mostrando que era necessário ter vontade:

Tendo entrado para o curso Anexo da Escola Superior de Agronomia e medicina Veterinária de Belo Horizonte, em 1930, ocasião esta que me achava 
empregado no comércio, vim a perder o ano por falta de pagamento, isto é, não poder, embora empregado, satisfazer as exigências, sendo um dos principais fatores a revolução. Continuando no ano seguinte (no curso anexo ainda), pude chegar até o presente ano a poder de muitos esforços, pois, trabalhando, pouco tempo sobrava-me para estudar, e apezar disso tinha que ajudar em casa com o pequeno ordenado que ganhava - no comércio elle é sempre miserável. Há mezes que me encontro desempregado, tendo lutado bastante para me manter na escola. So mesmo quem tem vontade de estudar é que consegue vencer as dificuldades que até aqui tenho vencido, sem a menor demonstração de desânimo (QUESTIONÁRIO do aluno de Medicina Veterinária Raphael Valentino, 23 fev. 1934) (Grifo do autor).

A vontade à que o estudante se refere diz respeito a lutar contra as dificuldades, vencendo-as, resistindo. Essas resistências são modos de transformação da realidade por meio de opções de vida: o pobre, em sua situação de precariedade e falta, trabalha e estuda, reinventa a sua condição para ter uma vida melhor. $\mathrm{O}$ estudante, ao se referir a ter vontade, depois dos seus relatos de dificuldades, mostrou que resistia às adversidades que a vida lhe trazia - falta de trabalho, de dinheiro, de condições de prosseguir com seus estudos, mas, mesmo assim, buscava meios de continuar, inclusive buscando auxílio junto à CEPEB.

A estreita relação entre pobreza e trabalho remete à condição de sujeito moral, ou seja, aquele indivíduo que carrega em si e vive de acordo com os princípios de uma norma constituída, que conduz o comportamento para o convívio consigo mesmo e com a sociedade. O esforço pessoal e a dedicação dos estudantes também foram mencionados por vários deles nos pedidos de auxílio. Esses enunciados aparecem misturados à ideia de rendimento escolar, de boas notas e de luta constante. $\mathrm{O}$ estudante Justino de Brito Vianna, do $5^{\circ}$ ano da Faculdade de Medicina, em 1934, contou que trabalhava no jornal Estado de Minas como revisor e ainda conciliava os estudos e a residência médica. O relato do estudante sobre sua luta pelo estudo mostra uma situação dura, mas que, com muito esforço e vontade, conseguia contornar:

Quando é o estudante que trabalha durante a noite para custear os seus estudos é fácil avaliar o sacrifício que se torna essa profissão [de revisor]. O serviço acaba em média entre 3 e 4 horas da manhã. Há aulas no período da manhã desde sete horas à hora do almoço. À tarde também há aulas, é preciso também estudar as lições do dia, frequentar os hospitais. Raramente se pode dormir um pouco durante o dia. Terminada a labuta do dia, há o jantar 
e a hora de entrar para o serviço de todas as noites. Embora o sono acumulado e o cansaço natural, é preciso prestar atenção para não deixar passar gato por lebre, para evitar as multas. E a realidade é que apezar do desperdício de energia e de saúde o revisor não pode muitas vezes tomar um copo de leite no serviço porque a pensão, os estudos, os livros, as despezas indispensáveis, os compromissos, não permitem gastos fora do orçamento. É essa a vida do revisor noturno, custeando honestamente a vida de estudante que se esforça durante o dia para compensar os sacrifícios. (QUESTIONÁRIO do aluno da Faculdade de Medicina Justino de Brito Viana, 13 de julho 1934)

Tais enunciados compõem o conjunto de relações discursivas que sustentam as já mencionadas por Foucault (2009, p.31) - estreiteza e singularidade do enunciado: a necessidade do trabalho para a vida do estudante pobre e a pobreza na qual se encontravam tinham no trabalho a garantia de manutenção do estudo e, assim, também a garantia de formação para ocupar uma função mais qualificada e melhor remunerada no futuro. E com essa exposição da verdade, os estudantes faziam uso de um apelo moral muito valorizado na época, o trabalho, descrevendo situações que eram sempre muito particulares e que só se repetiam no ritual de confissão da carência e dos meios insuficientes de que dispunham para enfrentá-la.

Quanto à situação familiar, os questionários trazem muitos elementos sobre a condição econômica e social das famílias dos estudantes na época. Alguns deles relataram que ainda residiam com suas famílias; outros, entretanto, moravam em pensões e de favor em casas de amigos.

O estudante João Mata Machado, que solicitou uma das 10 matrículas gratuitas da Faculdade de Direito que eram distribuídas pela CEPEB no ano de 1935, ao fazer uma crítica à situação de pobreza de sua família, teceu o seguinte comentário:

E agora, um ponto de interrogação que não poderia ser respondido pelo silêncio, porque só os pobres verdadeiramente pobres estão à altura de o compreender. De fato, como poderia viver uma família de nove pessoas, numa grande cidade, educando os filhos e etc., com tão irrisória quantia de dinheiro? São os grandes dramas obscuros vividos na realidade quotidiana de um lar paupérrimo. A luta surda e heróica, pelo 'pão nosso de cada dia'. As esperanças num futuro melhor para os filhos. (QUESTIONÁRIO do aluno da Faculdade de Direito João Mata Machado, 25 de setembro 1935) 
Quando o estudante se refere ao fato de que só os pobres verdadeiramente pobres estão à altura de o compreender, toma o sentido que Foucault (2009) define como uma vontade de verdade: trata-se de um procedimento de exclusão que se apoia nos suportes institucionais.

Os saberes são distribuídos, repartidos, valorizados e atribuídos nas sociedades de acordo com as relações que elas constituem. Assim, trata-se de uma vontade de verdade, que é determinada pelas ciências, pelas disciplinas, pelos discursos. Essa vontade de verdade está "assim apoiada sobre um suporte e uma distribuição institucional que tende a exercer sobre os outros discursos [...] uma espécie de pressão e como que um poder de coerção" (FOUCAULT, 2009, p.18).

Assim, a pobreza de que fala o estudante e que pode ser compreendida apenas por quem se supõe ser verdadeiramente pobre é uma formação discursiva constituída de acordo com o meio em que esse discurso circula e pela instituição que o concebeu: pela igreja? Pelo Estado? Pelas instituições de assistência? Pela própria população? Só entenderá o discurso quem estiver na ordem desse discurso, quem compreender o seu processo de formação ou os sentidos de seu enunciado.

Para Foucault (1999), os discursos deslocam-se e modificam-se de uma forma instável, e não absoluta. Quando alguém fala alguma coisa sobre algo, sempre está inserido em uma atmosfera discursiva. Os ditos verdadeiramente pobres poderão compreender a situação de que o estudante fala porque é pobre, e não um sujeito alheio ao discurso que ele produz sobre sua pobreza.

\section{Os enunciados das sindicâncias}

Conforme já abordado neste trabalho, os questionários comportam um espaço de preenchimento a partir das sindicâncias, para verificar a autenticidade das situações "confessadas" pelos estudantes. Essas sindicâncias eram feitas por pessoas indicadas tanto pelo estudante quanto pela comissão da CEPEB. A leitura e a análise dessa parte dos documentos fornecem importantes elementos para a apreensão dos enunciados que formam o discurso sobre a pobreza dos estudantes da UMG numa perspectiva diferente; qual seja: um espaço ocupado por aqueles que supõem ser idôneos e, portanto, têm autoridade para decidir pelo apoio ao solicitante. 
O primeiro elemento que se pode destacar nos enunciados das sindicâncias é o fator de relacionamento dos estudantes com as pessoas que eram indicadas a serem entrevistadas pela CEPEB sobre a veracidade das informações prestadas pelos requerentes. Em alguns trechos, observa-se que essas pessoas ditas idôneas atestavam seu relacionamento e conhecimento a respeito do estudante e de sua família: "Declaro que conheço o Sr. José Carlos e que, na verdade, necessita de auxílio da 'Caixa do Estudante Pobre'. Si assim declaro é porque sou conterrâneo delle e sei a situação de sua família” (QUESTIONÁRIO do estudante José Carlos da Cunha Oliveira, out. 1934). Em outra sindicância, o entrevistado Augusto Velloso afirmou: "Conheço o estudante Milton Caldeira Brant há muitos annos e posso affirmar que é um moço de exemplar proccedimento, muito intelligente e applicado" (SINDICÂNCIA do estudante Milton Caldeira Brant, Faculdade de Medicina, mar. 1934).

O que se pode perceber nessas passagens é, talvez, uma forma de amizade muito próxima daquilo que Foucault (1999) chamou de amizade epicurista. Segundo o autor, esse tipo de amizade envolve três fatores:

[...] primeiro, nascimento na utilidade; segundo, oposição entre a utilidade e desejabilidade da amizade; terceiro, enfim, o fato de que a oposição à amizade só é desejável se mantiver perpetuamente uma certa relação útil. Essa combinação entre utilidade e desejabilidade tem seu lugar e seu equilíbrio assim expressos: 'De todos os bens que a sabedoria proporciona para a felicidade da vida inteira, de longe o maior deles é a posse da amizade' (FOUCAULT, 1999, p.239).

Essa aproximação dos estudantes com sujeitos da sociedade, como médicos, professores, dentistas, políticos e até componentes da CEPEB, que eram citados como sindicantes, se fazia a partir de interesses em que esses três fatores mantinham uma combinação e um equilíbrio na relação entre a utilidade e a desejabilidade. Dessa forma, esses interesses poderiam também trazer vantagens a todos que participassem dela: para os estudantes, alguém com autoridade para atestar sua pobreza e atingir a finalidade do auxílio; e para os sindicantes, poderia significar um favor ou uma contribuição a um pobre, que mais tarde lhe poderia ser útil. Como observa Foucault, trata-se da "localização de reciprocidade (utilidade de nós mesmos para os outros e dos outros para conosco) no objetivo geral da salvação de si e do cuidado de si" (FOUCAULT, 2006, p.240). 
Mesmo não relatando sua condição diretamente à CEPEB, os estudantes tinham suas dificuldades e lutas retratadas pelas sindicâncias, só que em um tipo de discurso em que os enunciados se articulam de outra forma. Assim, em determinados questionários, os sindicantes procuram situar a condição financeira a atitudes morais que dizem respeito a suas aptidões intelectuais e à postura familiar e em sociedade:

Conheço de longa data o Sr. Alfredo da Costa Leite e não sei, ate hoje, de acto algum que o desabone. No Banco da Província do Rio Grande do Sul, galgou os mais altos postos a custa do seu trabalho, do seu esfforço e da sua intelligencia. Chefe de família exemplar. Aos seus cinco filhos procura dar uma educação que os ponha a salvo de desastres, no futuro. Como estudante, o Sr. Costa Leite é, entre seus collegas, o exemplo da tenacidade e perseverança (SINDICÂNCIA do estudante Alfredo da Costa leite, Curso de Medicina Veterinária e Agronomia, 15 ago. 1934).

Assim como no discurso dos estudantes sobre si mesmos, a questão do trabalho é valorizada. Na passagem citada, também se pode notar que uma das qualidades do estudante era sempre galgar os mais altos postos. Esse esforço é ressaltado com os enunciados tenacidade e perseverançaa busca pelo objetivo de prosseguir com os estudos e se formar.

$\mathrm{Na}$ sindicância do aluno Vicente Floriano, do $1^{\circ}$ ano do curso de Odontologia e Farmácia em 1934, já mencionado nas discussões sobre a justificativa de seu questionário, observam-se os enunciados que também fazem referência aos atributos morais, relacionando-os a certas qualidades dos mineiros:

Informo, a bem da verdade, que o Sr. Vicente Floriano Alves Ferreira necessita, realmente, dos bons auxílios da Caixa do Estudante Pobre 'Edelweiss Barcellos'. Trata-se de um moço que, a meu ver, merece toda a sua matricula paga pela Caixa, dada a sua precariedade financeira com que luta para vencer os seus dourados sonhos de estudos. O requerente é um desses raros moços que, pela sua modéstia, brio e trabalho, noticiam muito alto o nome da briosa gente mineira. Conheço muito bem a força de vontade do requerente. $\mathrm{E}$ prova disso está em que ele trabalha como Guarda Civil nesta Capital. Ganha, mais ou menos, $200 \$ 000$ por mez, e foi justamente depois que conseguiu essa modesta collocação que se matriculou no Gymnasio Mineiro, onde terminou o curso de humanidades no anno passado, à custa do seu ordenado que, por ser reduzido, obriga a ser deveras heróico, porque com a manutenção das despezas de primeira necessidade e pensão, digo livros, matricula, taxas, nada lhe sobrava monetariamente falando. Já agora, no curso superior, a situação delle 
é bem differente, dos mais ou menos $200 \$ 000$ tira mensalmente $110 \$ 000$ para a pensão e lavação de roupa, ficando $90 \$ 00$ para onerarios, bonde e despezas de estudo. (QUESTIONÁRIO do aluno de Odontologia e Farmácia Vicente Floriano, 06 de outubro 1934)

As características do estudante citadas pelo entrevistado - modéstia, brio e trabalho - compõem um conjunto de qualidades morais que define a postura do estudante de acordo com o relato transcrito. ${ }^{4}$ Segundo essa passagem, por ter essas características, o estudante seria merecedor do auxílio, pois, além de noticiar muito alto o nome da gente mineira, o estudante necessitava, verdadeiramente, do auxílio da CEPEB.

Um dos sindicantes convidados foi Carlos Drummond de Andrade. Ao ser entrevistado na sindicância do aluno do curso de Direito, Raymundo Augusto da Silva Maia, fez os seguintes comentários:

Conheço de longa data o requerente e posso informar ser verdadeiro tudo quanto alega. Trata-se de moço extremamente pobre, de origem humílima, trabalhador e dotado de grande fôrça de vontade. O auxílio que lhe prestar a Caixa 'Edelweiss Barcellos’ será útil e meritório. Sem esse auxílio não poderá ir avante. Considero o caso de Raimundo Maia típico do esforço individual, que reage contra toda espécie de circunstâncias desfavoráveis - meio, raça, físico, situação econômica, prejuízos sociais, etc. Ajudá-lo não será, pois, ato de caridade, mas de cooperação e interesse social. E será ainda efeito de estimular aos que, como ele, ocupam a camada mais ínfima, e dela desejam elevar-se a um destino melhor. Para mim, não interessa saber se Raimundo tem grande inteligência (e nem se pode exigir isso de todo estudante pobre). Basta saber que ele tem inteligência suficiente para manter a sua vontade num fim útil e fazer uma coisa que ninguém que o conheceu em menino o julgaria capaz de fazer: um curso superior. Faço meu pedido de auxílio (SINDICÂNCIA do estudante Raymundo Augusto da Silva Maia, 19 fev. 1934).

Para Drummond, o esforço e a vontade do estudante eram os elementos necessários para que o estudante fosse auxiliado, pois lutava contra todas as forças que poderiam afastá-lo de seu ideal de estudo e formação. A condição do estudante é ressaltada com os enunciados origem bumilima e extremamente pobre.

Ao discutirem esse relato da sindicância, Portes e Souza (2009) refletem sobre o posicionamento de Drummond em face do conceito de pobreza que se tinha na época, pois 
[...] surpreende por se contrapor à concepção, comum à época, de que apenas méritos individuais e incomuns ou capacidades intelectuais extraordinárias poderiam justificar tão grande ambição escolar por parte da população pobre. Contrapõe-se ainda à ideia de educação como um bem de luxo e não um direito social. Por outro lado, percebe-se em seu texto a transposição da questão da esfera do exclusivo atendimento individual para o plano de 'cooperação e interesse social' (PORTES; SOUZA, 2009, p.7).

O escritor destacou que a realização do curso superior para o estudante Raymundo era uma possibilidade de melhorar sua condição econômica e social, inclusive apontando que, no próprio meio de origem do estudante, as chances de estudo eram limitadas. E ainda mais: deixou transparecer que auxiliar um estudante pobre na condição de Raymundo seria um ato de interesse social - o interesse no auxílio dos pobres, que, por meio dos dispositivos da escolarização e da beneficência, se tornaria um fim útil.

Pelos enunciados das sindicâncias em que se faz referência aos estudantes, e não dos estudantes sobre si mesmos, como acontece nos questionários, percebe-se a tentativa de empregar o código moral ao comportamento dos estudantes nos enunciados dos sindicantes entrevistados. Estes sempre pontuam valores e regras emanados dos aparelhos prescritivos da sociedade, como nas expressões: precária situação, justiça, necessidade, exemplar conduta, inteligência, esforço e dificuldades.

Nos ofícios da CEPEB às escolas, à Reitoria da UMG e às demais instituições, foram localizados poucos enunciados que fazem referência aos estudantes, apesar de se tratar de uma documentação pertencente à própria CEPEB. Provavelmente, isso se deve à formalidade e busca de objetividade com que a direção da CEPEB se relacionava com as outras instituições para as quais informava apenas as listas de alunos beneficiados, pagamentos e balancetes.

Entretanto, foram encontradas algumas passagens que merecem ser apresentadas aqui neste trabalho. Na lista provisória encaminhada pela CEPEB, em março de 1932, aparecem duas anotações sobre alunos que não deveriam ser beneficiados: "João Pimenta da Veiga - deve-se evitar auxiliá-lo, porque se casou há menos de um mez e disse que, por este motivo, 'era mais digno de commiseração, sendo este do $4^{\circ}$ ano do curso de Direito"; e ainda: "Segundo pedido feito por Dr. Paulo Costa, não devem ser auxiliados, por falta absoluta de interesse pelos estudos, os Srs. 
Carlos Etienne Castro, Adolpho Julio Correa Pinto e Joanna Loureiro", esses três da Escola de Engenharia. (LISTA DE AUXILIOS da Caixa do Estudante Pobre Edelweis Barcellos, 04 de março de 1932)

O que se pode notar, nessas passagens, é que, por condutas não aprovadas pela diretoria da CEPEB, os alunos já referidos não foram beneficiados. $\mathrm{O}$ aluno João Pimenta da Veiga, por se referir à ajuda como uma esmola ou uma ação de compaixão, e os outros três alunos do curso de Engenharia, pela falta de interesse pelos estudos.

Mais uma vez, toma-se o apelo moral, pois a atenção aos valores e cumprimento das regras contribuíam para a formação do caráter. Tal comportamento seria elemento essencial para obter benefício por intermédio das associações estudantis e assim fazer parte do seleto grupo de estudantes do ensino superior. A disciplinarização dos estudantes, em torno e por meio dessa moral, determinava quem poderia ser ajudado ou não. Para compreender essas relações, Foucault (2008) procurou definir o que seria a normatização disciplinar:

A disciplina, é claro, analisa, decompõe os indivíduos, os lugares, os tempos, os gestos, os atos, as operações. Ela os decompõe em elementos que são suficientes para percebê-los, de um lado, e modificá-los, de outro [...] a disciplina classifica os elementos assim identificados em função de objetivos determinados. Quais são os melhores gestos a fazer para obter o melhor resultado? [...] A disciplina estabelece os procedimentos de adestramento progressivo e de controle permanente e, enfim, a partir daí, estabelece a demarcação entre os que serão considerados inaptos, incapazes e os outros (FOUCAULT, 2008, p.75).

Então, a normatização disciplinar que determina os comportamentos, aceitáveis ou não, também estabelece dispositivos de controle. Pode-se entender que a CEPEB, mediante suas regras de beneficiamento, impõe essa normatização disciplinar: o estudante era estudioso? Tinha bom comportamento? Era reconhecidamente esforçado? Por meio dessas indagações de fundo moral, os três estudantes foram excluídos da lista dos beneficiados pela CEPEB.

A normalização disciplinar consiste em primeiro colocar um modelo, um modelo ótimo que é construído em função de um certo resultado, e a operação de normalização disciplinar consiste em procurar tornar as pessoas, os gestos, os atos, conformes a esse modelo, sendo normal precisamente quem 
é capaz de se conformar com essa norma e o anormal quem não é capaz (FOUCAULT, 2005, p.75).

Nas sindicâncias, os enunciados demonstram uma grande e quase que exclusiva preocupação com o comportamento e o modo de vida do estudante, posto que se destacam enunciados sobre a moralidade e carência. E isso está bem mais presente do que nos questionários respondidos pelos próprios estudantes.

\section{Considerações finais}

O sentido da pobreza que aqui se procurou destacar vai além do sentido econômico do termo. Para tal, foi necessário realizar um estudo sobre a formação das associações estudantis e se dedicar exclusivamente a certo período da história da UMG na passagem da CEPEB como auxílio aos estudantes pobres. Notou-se, também, que a CEPEB tinha o intuito não só econômico, mas também moral, que se voltava para uma pretensa formação social do estudante: além de dispositivos de inserção na sociedade, ela criava também ligações entre os estudantes e compromissos de honra, constituídos não só pelos empréstimos concedidos pela assistência, como ainda pela preocupação em desenvolver o aluno do ponto de vista physico, intellectual e moral (sic). Como apontou Foucault (1998), esses dispositivos fazem com que os indivíduos busquem sua própria substância moral por meio de uma construção de si mesmos, relacionada também a prescrições, interdições, normas e condutas que o meio condiciona.

Os enunciados que compõem esses documentos da CEPEB apontaram para a existência de uma formação discursiva sobre a pobreza dos estudantes, que vai além das carências materiais. Eram estabelecidas relações entre esses estudantes e a sociedade em geral, em que aconteciam manifestações de amizade, dependência e auxílio. A singularidade desses enunciados, como mostra Foucault (2009), é resultado da dinâmica histórica dos discursos: podem circular, serem interrompidos, cerceados, mas, no entanto, irrompem a qualquer momento e em qualquer espaço, de acordo com as relações que se estabelecem, e com isso se tornam singulares em sua existência, mas sem deixarem de compor o objeto do discurso. 
A pobreza que se manifesta nos enunciados dos discursos encontrados nos documentos mostra que os estudantes considerados pobres constituíam práticas de si: buscavam comportar-se mediante uma moral coletiva, formando obrigações e vínculos que orientavam suas condutas. Ao mesmo tempo, as relações de poder permeavam essa constituição individual e coletiva, com dispositivos de controle da população dos estudantes, como era o funcionamento da CEPEB e os efeitos de verdade dentro dos discursos que se criavam para alcançar o benefício.

Essa pobreza não era somente a ausência de recursos: era também a falta de trabalho ou o trabalho precário para sustento do curso, a hospedagem na casa dos amigos, o empréstimo dos livros, as relações com pessoas que poderiam atestar a boa conduta e a postura moral e humilde do estudante. Era não ter o que vestir, ter que vender a roupa do corpo ou ter que abandonar os estudos pela falta de pagamento das taxas. Era sustentar a família e ainda buscar possibilidades de custear as mensalidades. Trata-se de um modo de vida, em que a CEPEB seria uma forma de resistência em busca de um objetivo: a conclusão do curso superior, que poderia proporcionar oportunidades de melhoria da condição individual e familiar desses estudantes.

Portanto, ao analisar os discursos sobre a pobreza dos estudantes da UMG presentes nos documentos da CEPEB, pode-se notar que a pobreza relatada pelos estudantes não era apenas a carência material: as carências culturais, intelectuais e sociais também definiam a situação do estudante pobre da UMG, que buscava estratégias para prosseguir em seus estudos. Entretanto, os discursos estavam inscritos numa construção de jogos de verdade, que correspondiam às regras da CEPEB para atendimento dos pedidos e à dinâmica de análise e concessão das bolsas, em que os estudantes procuravam ser considerados verdadeiramente merecedores de auxílio. 


\section{NOTAS}

1 Os principais contemporâneos do processo de constituição da UMG que realizaram registros da história e memória da instituição foram Moraes (1972) e Penna (1997), além das narrativas de Lúcio José dos Santos nos diversos documentos publicados na Revista da UMG e na Revista do Arquivo Público Mineiro, e ainda Francisco Mendes Pimentel, com o livro O conflito de 18 de novembro. Nas últimas décadas, autores como Dias (1997), Portes (1993, 2001, 2003, 2005, 2006), Christófaro (2012, 2013), Starling, Figueiredo e Furtado (2007), Starling e Almeida (2008), Starling e Duarte (2009), Starling, Germano e Marques (2011), Starling e Figueiredo (2012) e Maciel e Malard (2013) realizaram estudos sobre a constituição e implantação dos cursos superiores em Minas Gerais, a assistência estudantil e a criação da Universidade de Minas Gerais.

2 Foram encontradas três rainhas dos estudantes eleitas entre os anos de 1927 e 1936: Cecy Gontijo, Edelweiss Barcellos e Daisy Prates. Tanto Edelweiss Barcellos quanto Daisy Prates eram oriundas de famílias letradas, cujos pais ocupavam posição de destaque no mundo acadêmico. Edelweiss Barcellos era filha de Francisco de Assis Barcellos Correia, desembargador e professor da Escola de Engenharia, e Daisy Prates era filha de Lincoln Prates, professor e vice-diretor da Faculdade de Direito em 1930. Não encontramos dados sobre a família de Cecy Gontijo. Entretanto, nenhuma das rainhas ingressou em qualquer curso superior da UMG, apesar de atuarem ativamente junto aos estudantes, professores e sociedade em geral, inclusive garantindo o funcionamento da assistência estudantil em um período de crise na UMG iniciado em 1930. Com isso, além de "figuras decorativas", como era a rainha Cecy Gontijo, Edelweiss e Daisy tiveram um papel de destaque, ação e trabalho, mesmo com as limitações que a educação feminina do contexto impunha. Todas elas foram eleitas por meio de concurso realizado entre os estudantes de todos os cursos superiores de Belo Horizonte e, ainda, estudantes do Ginásio Mineiro e Colégio Arnaldo, promovido pelo Semanário Acadêmico A Caveira, que era produzido e publicado pelos estudantes da Faculdade Livre de Medicina. O primeiro concurso foi realizado em 1927, elegendo Cecy Gontijo. O segundo concurso foi realizado em 1929, quando foi eleita Edelweiss Barcellos, e o terceiro concurso foi realizado em 1932, que elegeu Daisy Prates. Para maiores informações, ver Christófaro (2012).

3 Os documentos reproduzidos neste estudo são reproduções digitalizadas e impressas cedidas pela antiga Diretoria de Serviços Gerais (DSG) da UFMG, Atualmente, os originais se encontram no Projeto República, na Biblioteca Universitária da UFMG, Campus Pampulha.

4 Segundo Michel Foucault, moral é “o conjunto de valores e regras de ação propostas aos indivíduos e aos grupos por intermédio de aparelhos prescritivos diversos, como podem ser a família, as instituições educativas, a Igreja, etc.” (FOUCAULT, 1998, p.26). Esse conjunto de regras e valores pode ser transmitido de maneira explícita ou difusa, mas, de qualquer forma, conduz o comportamento dos indivíduos pelos modos de sujeição, que são "a maneira pela qual o indivíduo estabelece sua relação com essa regra e se reconhece como ligado à obrigação de pô-la em prática” (FOUCAULT, 1998, p.27). 


\section{REFERÊNCIAS}

ABREU JÚNIOR, Laerthe de Moraes. Apontamentos para uma metodologia em cultura material escolar. Pro-Posições (Unicamp), Campinas, v.16, n.1, p.145-164, 2005.

ARQUIVO da Caixa do Estudante Pobre "Edelweiss Barcellos" - 1932 a 1935.

CANDIOTTTO, Cesar. Foucault e crítica da verdade. Belo Horizonte: Autêntica, 2010.

CHRISTÓFARO, Alice C. A Caixa do Estudante Pobre Edelweiss Barcellos: discursos sobre a pobreza dos estudantes da Universidade de Minas Gerais (1932-1935). 150f. 2012. Dissertação (Mestrado) - Faculdade de Educação, Universidade Federal de São João delRei, São João del-Rei, 2012.

CHRISTÓFARO, Alice C. As ações de associativismo estudantil para assistência ao estudante pobre na Universidade de Minas Gerais (1912-1936). In: CONGRESSO BRASILEIRO DE HISTÓRIA DA EDUCAÇÃO, 8., 2013, Cuiabá/MT. Anais... Cuiabá: Sociedade Brasileira de História da Educação, 2013.

DIAS, Fernando Correia. Universidade Federal de Minas Gerais: projeto intelectual e político. Belo Horizonte: Ed. da UFMG, 1997.

ESTATUTO da Associação Universitária Mineira (AUM). Belo Horizonte, 1931.

FOUCAULT, Michel. História da sexualidade 2: o uso dos prazeres. 8ed. Rio de Janeiro: Graal, 1998.

FOUCAULT, Michel. Em defesa da sociedade: curso no Collège de France (1975-1976). São Paulo: Martins Fontes, 1999.

FOUCAULT, Michel. História da sexualidade 3: o cuidado de si. 8ed. Rio de Janeiro: Graal, 2005.

FOUCAULT, Michel. A hermenêutica do sujeito. São Paulo: Martins Fontes, 2006. (Coleção Tópicos).

FOUCAULT, Michel. Segurança, território e população. Curso no Collège de France (19771978). Trad. Eduardo Brandão. São Paulo: Martins Fontes, 2008.

FOUCAULT, Michel. A arqueologia do saber. 7ed. Rio de Janeiro: Forense Universitária, 2009.

FOUCAULT, Michel. A ordem do discurso: aula inaugural no Collège de France, pronunciada em 2 de dezembro de 1970. 20ed. São Paulo: Loyola, 2010.

LIMA, Mário Hélio Trindade de. Exclusão social: representações sociais da pobreza urbana no Brasil. Vitória: EDUFES, 2005.

LISTA DE AUXILIOS da Caixa do Estudante Pobre Edelweis Barcellos, 04 de março de 1932.

MACIEL, Carlos Alberto; MALARD, Maria Lúcia (Orgs.). Territórios da Universidade: permanências e transformações. Belo Horizonte: Ed. da UFMG, 2013.

MORAES, Eduardo R. Affonso de. História da Universidade Federal de Minas Gerais. Belo Horizonte: Imprensa da Universidade Federal de Minas Gerais, 1972. 2v.

PENNA, Octavio. Notas cronológicas de Bello Horizonte. Belo Horizonte: Fundação João Pinheiro, Centro de Estudos Históricos e Culturais, 1997.

PIMENTEL, Francisco Mendes. O conflito de 18 de novembro. Belo Horizonte: Imprensa Oficial de Minas Gerais, 1931.

PORTES, Écio Antônio. Trajetórias e estratégias escolares do universitário das camadas populares. 248f. 1993. Dissertação (Mestrado) - Faculdade de Educação, Universidade Federal de 
Minas Gerais, Belo Horizonte, 1993.

PORTES, Écio Antônio; SOUZA, Letícia Pereira de. Do lado bom da barreira: trajetórias e estratégias sociais e escolares de Raymundo Augusto da Silva Maia (1900-1990). In: CONGRESSO DE PESQUISA E ENSINO EM HISTÓRIA DA EDUCAÇÃO EM MINAS GERAIS, 5., 2009. Montes Claros: UNIMONTES, 2009. v.1, p.1-15. Disponível em: <http://www.congressods.com.br/vcopehe/images/trabalhos/4.genero_etnia_e_geracao/3.Ecio\%20Antonio\%20Portes.pdf>. Acesso em: 04 jun. 2010.

PORTES, Écio Antônio; SOUZA, Letícia Pereira de. Trajetórias escolares e vida acadêmica do estudante pobre da UFMG: um estudo a partir de cinco casos. 267f. 2001. Tese (Doutorado) - Faculdade de Educação, Universidade Federal de Minas Gerais, Belo Horizonte, 2001. PORTES, Écio Antônio; SOUZA, Letícia Pereira de. A caixa dos pobres - a ação efetiva da assistência na permanência de estudantes pobres na Universidade de Minas Gerais (UMG): 1932-1935. Cadernos de História da Educação, Uberlândia, n.2, p.29-38, jan./dez. 2003.

PORTES, Écio Antônio; SOUZA, Letícia Pereira de. O estudante pobre na Universidade Federal de Minas Gerais: uma abordagem histórica. Educação em Revista, Belo Horizonte, v.41, p.111-133, 2005.

PORTES, Écio Antônio; SOUZA, Letícia Pereira de. Algumas dimensões culturais da trajetória dos estudantes pobres no ensino superior público: o caso da UFMG. Revista Brasileira de Estudos Pedagógicos, Brasília, v.87, n.216, p.220-235, maio/ago. 2006.

QUESTIONÁRIO do aluno da Faculdade de Direito João Mata Machado, 25 de set. 1935.

QUESTIONÁRIO do aluno de Medicina Veterinária e Agronomia Abelardo de Andrade Barroso, 14 de mai. 1935.

QUESTIONÁRIO do aluno de Medicina Veterinária Raphael Valentino, 23 fev. 1934.

QUESTIONÁRIO do aluno de Odontologia e Farmácia Vicente Floriano, 06 de out. 1934.

QUESTIONÁRIO do estudante José Carlos da Cunha Oliveira, out. 1934.

SINDICÂNCIA do estudante Raymundo Augusto da Silva Maia, 19 fev. 1934.

SINDICÂNCIA do estudante Milton Caldeira Brant, Faculdade de Medicina, mar. 1934.

SINDICÂNCIA do estudante Alfredo da Costa Leite, Curso de Medicina Veterinária e Agronomia, 15 ago. 1934.

STARLING, Heloísa; ALMEIDA, S. R. G. (Orgs.). Sentimentos do mundo: ciclo de conferências dos 80 anos da UFMG. Belo Horizonte: Editora da UFMG, 2008.

STARLING, Heloísa; DUARTE, R. H. (Orgs.). Cidade Universitária da UFMG: história e natureza. Belo Horizonte: Editora da UFMG, 2009.

STARLING, Heloísa; FIGUEIREDO, Lígia Beatriz de Paula. Engenharia: história em construção. Belo Horizonte: Editora da UFMG, 2012.

STARLING, Heloísa; FIGUEIREDO, Lígia Beatriz de Paula; FURTADO, Junia Ferreira (Orgs.). Odontologia: história restaurada. Belo Horizonte: Editora da UFMG, 2007.

STARLING, Heloísa; FIGUEIREDO, Lígia Beatriz de Paula; MARQUES, Rita de Cássia (Orgs.). Medicina: história em exame. Belo Horizonte: Editora da UFMG, 2011. 
Recebido em: 24/03/2013

Aprovado em: 02/09/2013

\section{Contato:}

Departamento de Ciências da Educação

Universidade Federal de São João del Rei

Praça Frei Orlando, 170

Centro

CEP $36307-352$

São João del-Rei | MG | Brasil 